\title{
Investigating Multicomponent Approaches for the Site-Selective Conjugation of Native Proteins
}

Charlotte Sornay ${ }^{1}$, Steve Hessmann ${ }^{2}$, Stéphane Erb², Igor Dovgan ${ }^{1}$, Anthony Ehkirch ${ }^{2}$, Thomas Botzanowski ${ }^{2}$, Sarah Cianferani², Alain Wagner ${ }^{1}$, Guilhem Chaubet ${ }^{1 *}$

\author{
AUTHOR ADDRESS \\ 'Bio-Functional Chemistry (UMR 7199), LabEx Medalis, University of Strasbourg, 74 Route du Rhin, \\ 67400 Illkirch-Graffenstaden, France \\ 'Laboratoire de Spectrométrie de Masse BioOrganique (LSMBO), Université de Strasbourg, CNRS, \\ IPHC UMR 7178, 67000 Strasbourg, France
}

\section{KEYWORDS}

Bioconjugation; multicomponent reaction; antibodies; antibody-drug conjugates

\begin{abstract}
Site-selective modification of proteins has been the object of intense studies over the past decades, especially in the therapeutic field. Prominent results have been obtained with recombinant proteins, for which site-specific conjugation is made possible by the incorporation of particular amino acid residues or peptide sequences. While mutant proteins take most of the spotlight, native and natural proteins have been left in the shadow and site-selective methods to conjugate these are underexplored. In addition, while these few methods give good results on small to medium-sized proteins, most of them tend to fall short whenever applied to bigger constructs such as antibodies. To address this limitation, we reasoned that aiming at the simultaneous conjugation of two amino acid residues should give higher chances of developing a site-selective strategy compared to the large majority of existing methods that solely target a single residue. We opted for the Ugi four-center three-component reaction to implement this idea, with the aim of conjugating the side-chain amine and carboxylate groups of two neighbouring lysine and aspartate/glutamate. Herein, we show that this strategy can give access to valuable conjugates bearing several different payloads, and limits the potential conjugation sites to only six on the model antibody trastuzumab.
\end{abstract}

Proteins posttranslational modifications (PTM) is Nature's way of generating a rich and diverse proteome from a more limited genetic coding capability: affecting 15 out of the 20 most common proteinogenic amino acids, PTM could indeed lead to more than a 100 -fold increase in proteins diversity in a living organism compared to the estimated number that should be generated from its encoding genome.1,2 Phosphorylation, glycosylation, methylation and acylation are the most representative examples of the $>200$ different types of PTM known to tune proteins' physicochemical properties and biological functions. First occurrences of intentional, man-made - artificial - proteins modifications using a defined chemical - thus excluding the food-related Maillard reaction for example - could be dated back to the use of formaldehyde in the tanning industry or for the production of toxoids, 3,4 which evolved later on to immunization studies using chemically-modified bovine serum albumin in the 1900s and eventually led to Landsteiner's synthetic haptenes studies. ${ }^{5,6}$ The field of protein modification has since largely benefited from the understanding of proteins' and amino acids' structures coupled to the parallel appearance of more efficient and precise analytical tools. This finally resulted in the development of bioconjugation reagents with excellent chemoselectivity towards various amino acids' side chains groups (i.e. residue-selectivity) that translated into major applications, notably in the pharmaceutical field with the generation of protein-fluorophore adducts for trafficking studies, or the polyethyleneglycol chains functionalization (PEGylation) of proteins to give less-immunogenic and more plasma-stable conjugates..$^{7,8}$

However, site selectivity quickly emerged as the main limitation of chemoselective strategies, due to the presence of multiple copies of each type of amino acid residue at the surface of proteins. Regioselective methods were thus developed and are currently dominated by the use of recombinant proteins, incorporating exogenous amino acid residues - natural or unnatural - or peptide sequences that can be specifically targeted by a tailored reagent or strategy..$^{9-11}$ In comparison, and despite recent advances in the field, site-selective chemical strategies for the conjugation of native and natural proteins are not as well-developed and tend to give disappointing results when applied to large proteins. ${ }^{12-31}$ This justifies the need to pursue investigations towards a general conjugation procedure that could be applicable to all sorts of native and natural proteins, with various sizes and functions.

As the vast majority of protein conjugation strategies focus on the modification of a unique residue, we hypothesized that targeting two different amino acid side chains simultaneously would lower the enormous subset of possibilities given by single-residue bioconjugation techniques, thus increasing our 
chances of developing a site-selective method by minimising the number of potentially reactive sites. In order to do so, we elected the Ugi four-centre three-component reaction (U-4C-3CR) for the concomitant conjugation of two spatially close lysine and aspartate (or glutamate) residues (Figure 1). It was expected that close amine/carboxylate pairs would give the expected bis-amide final product in the presence of an aldehyde and an isocyanide, while lysines that are not in the vicinity of a carboxylate moiety could form imines but would not give any productive Ugi reaction. ${ }^{32,33} \mathrm{~A}$ solution of hydroxylamine would then simply be added at the end of the reaction to regenerate the amino groups of these lysine residues that did not partake in the multicomponent reaction. While the Ugi reaction has been the object of extensive studies for the conjugation and stapling of peptides, only a handful of publications reports the use of proteins as coupling partners. ${ }^{34-38}$ Most notably, all these strategies use the four-component version of the Ugi reaction (U-4CR) - i.e., they only target a single site at the protein surface, whether it be an amino acid residue (lysines or aspartates / glutamates) or aldehydes from the glycan portion after periodate oxidation - and necessitate excessive amounts of reagents (up to 4000 equivalents) and long reaction times (up to 4 days). In addition, the absence of thorough analytical investigations precludes the conclusion that the Ugi reaction, and not an uncontrolled side reaction, was indeed responsible for the bioconjugation. This aspect is of prime importance in our case, due to the probable competition of the Passerini reaction for the conjugation of aspartate / glutamate residues that could erode the potential site-selectivity of the U-4C-3CR.
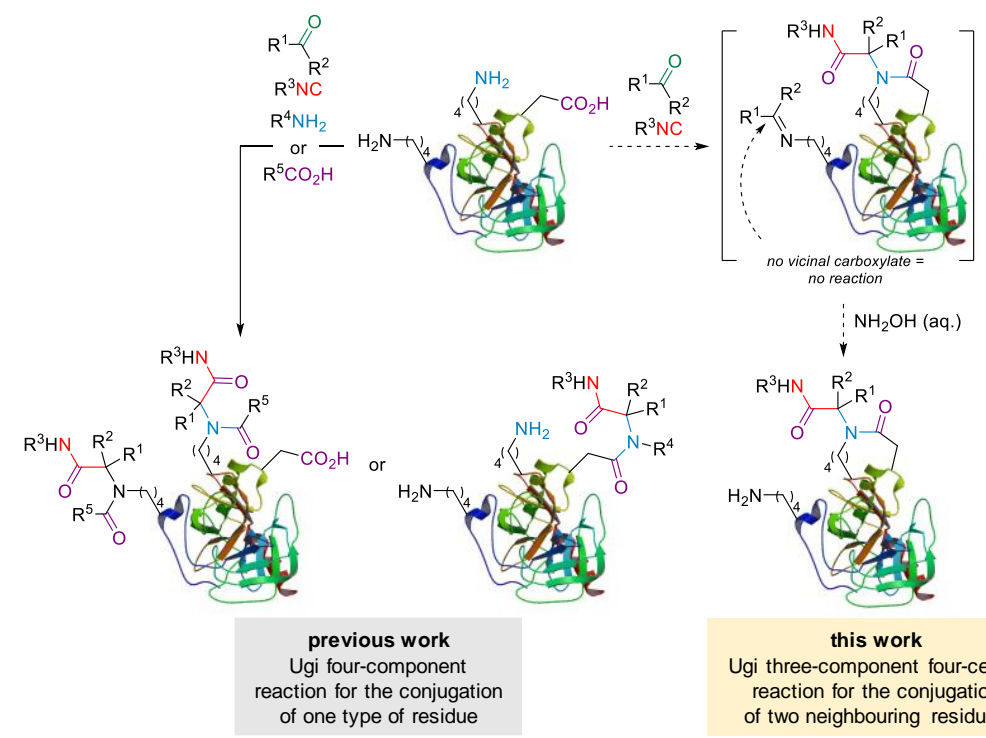

$\mathrm{NH}_{2} \mathrm{OH}$ (aq.)

$r$

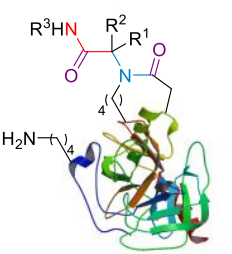

this work

Ugi three-component four-center

reaction for the conjugation

of two neighbouring residues

Figure 1: application of the Ugi reaction to the bioconjugation of native proteins

As we ambition to develop a site-selective strategy that could be applied to the conjugation of large proteins, we selected trastuzumab $(\sim 150 \mathrm{kDa})$ as our model protein, a FDA-approved antibody marketed as Herceptin that is used for the treatment of breast cancer by targeting the overexpressed HER2 receptors. ${ }^{39}$ We embarked upon the study of the feasibility of our strategy by reacting it with various amounts of the model TAMRA aldehyde 1a and tert-butyl isocyanide 2a (Figure 2, a). The reaction was set up in phosphate-buffered saline (PBS) buffer (1x, pH 7.5, $137 \mathrm{mM} \mathrm{NaCl})$ - to avoid the use of amine or carboxylate buffers that could compete with the antibody for the Ugi reaction - and average degrees of conjugation (DoC) and conversion rates were determined by native mass spectrometry (native MS). We were delighted to see that even low concentrations of reagents gave positive results in just $16 \mathrm{~h}$ at $25{ }^{\circ} \mathrm{C}$ without the need of any catalyst or imine preformation. ${ }^{40,41}$ We also observed a strong influence of the aldehyde-to-isocyanide ratio on the reaction outcome, with better conversion rates and DoC obtained with equimolar or near equimolar ratios. Increasing the amounts of both aldehyde and isocyanide led to higher DoC and conversion rates, however, only to a certain extent: a plateau was reached when large excess were used (i.e. $\geq 60: 120 \mathbf{1 a} / \mathbf{2 a}$ ), possibly indicating a limit in the number of functionalization sites on trastuzumab. This hypothesis was reinforced when looking at the conjugates distribution: for the highest conversions (i.e. $>80 \%$ ), the maximal DoC value observed was only 6 and represented less than $5 \%$ of all conjugates. Excellent conversion could be obtained with a narrower DoC distribution when 45 equivalents of both 1a and 2a were employed, with adducts with DoC > 3 (D4 and D5; Figure 2, b) representing a negligible fraction of all conjugated species. Control experiments were also done at this stage, where trastuzumab was reacted in the absence of either aldehyde 1a or isocyanide $\mathbf{2} \mathbf{a}$, leading to no conjugation in both cases and thus proving the multicomponent aspect of 
the reaction (see ESI and Figure S2 for more details). Prolonging the reaction time up to 2.5 days or heating at $37{ }^{\circ} \mathrm{C}$ resulted in improved conversions but extended DoC distribution - up to D4 when a $20 / 40 \mathbf{1 a} / \mathbf{2 a}$ ratio was utilised - while performing the reaction at $4{ }^{\circ} \mathrm{C}$ had the opposite effect. On the other hand, varying the $\mathrm{NaCl}$ concentration or the $\mathrm{pH}$ of the buffer solution led to no noticeable change (see ESI and Figure S3 for more details). Thus, optimal conditions for the conjugation of trastuzumab were determined to be 45 equivalents of both $1 \mathrm{a}$ and $2 \mathrm{a}$ in PBS buffer $(1 \mathrm{x}, 137 \mathrm{mM}$ of $\mathrm{NaCl}, \mathrm{pH} 7.5)$, with a reaction time of 16 hours at $25^{\circ} \mathrm{C}$, offering the best compromise between conversion and DoC distribution.

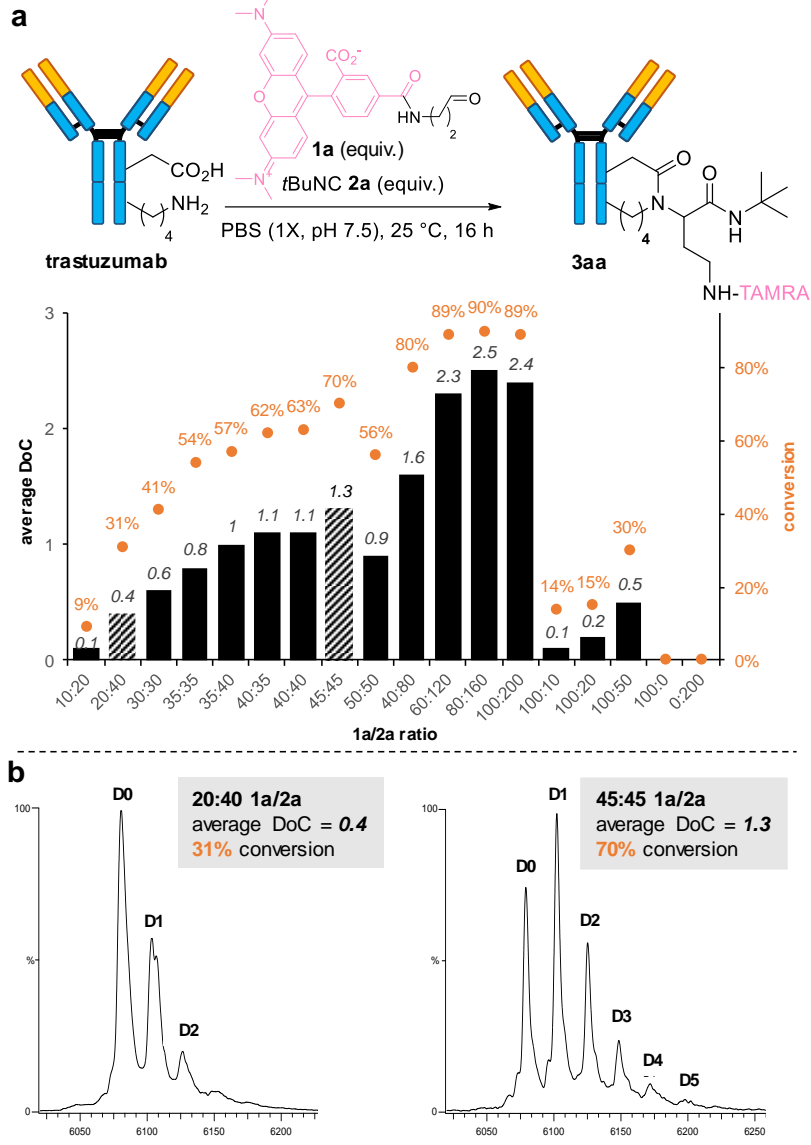

Figure 2: Ugi four-component three-centre reaction on trastuzumab. (a) Influence of aldehyde 1a to isocyanide 2a ratio on trastuzumab's average DoC, determined by native MS. (b) Native mass spectra of the resulting functionalized trastuzumab (zoom on the $24+$ charged state); reaction conditions: 1 a (20 or 45 equiv.), $2 a$ (40 or 45 equiv.), $\mathrm{PBS} 1 \mathrm{x}(137 \mathrm{mM} \mathrm{NaCl}, \mathrm{pH} 7.5), 25^{\circ} \mathrm{C}$, $16 \mathrm{~h}$; conversion $=100-\% \mathrm{D} 0$.

With this set of conditions in hands, we then turned our attention towards the development of a 'plugand-play' version of our strategy, ${ }^{16,42,43}$ by first incorporating an azide group onto trastuzumab - via our multicomponent strategy - that could then be easily functionalized by strain-promoted azide-alkyne cycloaddition (SPAAC) with various payloads (Figure 3, a). For practical synthetic reasons, it was found easier to have the azide group borne by the aldehyde component and azide-containing aldehyde $\mathbf{1 b}$ was thus easily synthesized in three steps from commercially available tetraethylene glycol and reacted with $\mathbf{2 a}$ and trastuzumab under our optimal conditions. The resulting conjugate $\mathbf{3 b a}$ was then purified and subjected to SPAAC with the bicyclononyne $(B C N)$ derivative $4 a$, equipped with a cyanine- 5 fluorophore, delivering the functionalized adduct 5 a whose average DoC was determined by native MS. It is important to stress that partial precipitation was always observed due to the hydrophobic nature of the cyanine- 5 payload, thus slightly impacting the average $\mathrm{DoC}$ and conversion rate values.

Screening different aldehyde-to-isocyanide ratios, we found that conversion and average DoC values were slightly lower with $\mathbf{1 b}$ than with $\mathbf{1 a}$ in general (Figure 3, b). However, DoC distribution turned out to be better, with D4 being the highest conjugated species observed across all conducted experiments and representing $<8 \%$ of all conjugates. Stability studies of conjugate $5 \mathrm{a}$ (see ESI and Figure S4 for more details), conducted for five days in different media, showed no apparent decomposition in human plasma and a good stability in PBS at various $\mathrm{pH}$. 


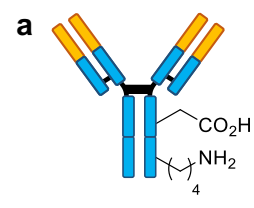

$$
\begin{aligned}
& \text { 1b (equiv.) } \\
& 2 \mathrm{2a} \text { (equiv.) } \\
& \mathrm{PBS}(1 \mathrm{X}, \mathrm{pH} 7.5),
\end{aligned}
$$
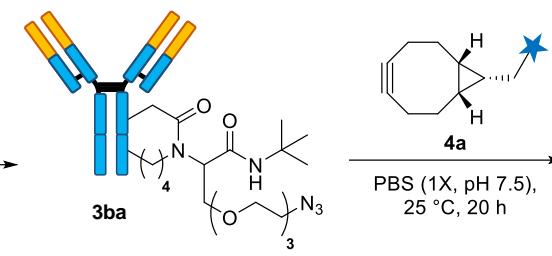

PBS (1X, pH 7.5), $25^{\circ} \mathrm{C}, 20 \mathrm{~h}$
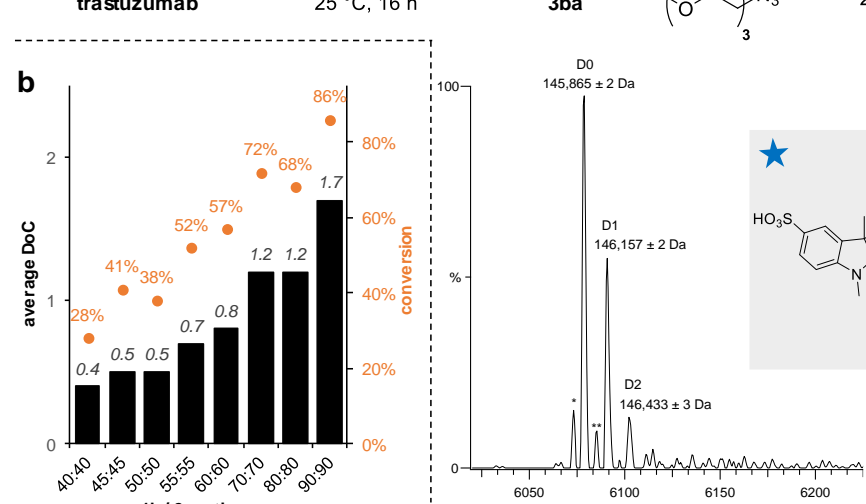

$1 \mathrm{~b} / 2 \mathrm{a}$ ratio

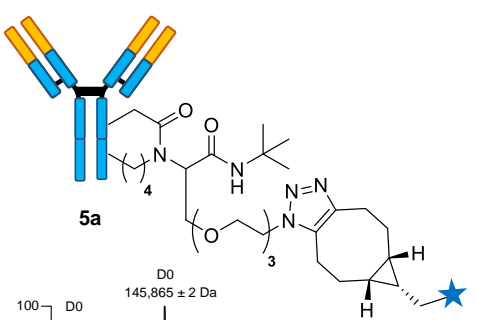

Figure 3: 'Plug-and-play' strategy: (a) conjugation of trastuzumab with the azide-containing aldehyde $\mathbf{1 b}$ and isocyanide $\mathbf{2 a}$ followed by functionalization with strained alkyne $4 a$ and native mass spectra of the different adducts (zoom on the 24+ charged state - reaction conditions corresponding to the spectra: "plug step": 3 (45 equiv.), tBuNC (45 equiv.) in PBS 1x (137 mM of NaCl, $\mathrm{pH} 7.5), 25^{\circ} \mathrm{C}, 16 \mathrm{~h}$; "play step": $5 a$ (10 equiv.) in PBS 1x (137 mM of NaCl, pH 7.5), $\left.25^{\circ} \mathrm{C}, 20 \mathrm{~h}\right)$; (b) optimization of the "plug step" (average DoC and conversion rates determined by native MS analysis of the corresponding conjugates 5 a).

Having developed a set of robust and modular conditions leading to stable constructs, the versatility of our strategy at both the plug and the play stages was then evaluated by screening various isocyanides and diversely functionalized strained alkynes. As shown in Figure 4, the reaction proceeded smoothly and gave better average DoC values with commercially available isopropyl isocyanide $\mathbf{2} \mathbf{b}$, cyclohexyl isocyanide $\mathbf{2 c}$ and ethyl isocyanoacetate $\mathbf{2 e}$, while diethyl isocyanomethylphosphonate $\mathbf{2 f}$ led to no visible conjugation. Different isocyanides were also newly synthesized with the aim of incorporating other reactive groups onto trastuzumab: $\mathbf{2} \mathbf{g}$ was accessed in a single step from $\mathbf{2 e}$, while isocyanides $\mathbf{2 h}-\mathbf{2 m}$ were easily generated from the known benchstable $p$-nitrophenol carbonate $\mathbf{2 n}$. ${ }^{44}$ Mixed results were obtained for the conjugation of trastuzumab with this set of compounds however, with $2 \mathbf{i}$ being the only isocyanide to give acceptable conversion and average DoC values. Overall, small and apolar isocyanides seem to work best for this transformation, which could possibly indicate that reactive conjugation sites are located in hydrophobic pockets.

As for the play stage, starting from conjugate $3 \mathbf{b c}$, complete conversions for the SPAAC reaction were consistently observed with BCN motifs, allowing the introduction of various payloads onto the antibody: mass spectrometry and NMR tags (4b and $\mathbf{4 d}$ ), iminobiotin (4c), or 20-mer oligonucleotides (4e and $\mathbf{4 f}$ ). Switching to dibenzocyclooctyne (DBCO) groups, we successfully generated the antibody-drug conjugate $(A D C) \mathbf{5 g}$ by incorporating the monomethyl auristatin $E$ (MMAE) drug (4g), connected to the strained alkyne scaffold by a cleavable valine-citruline linker. Analysis by native MS after purification by gel filtration chromatography showed an incomplete conversion during the SPAAC reaction but an average drug-to-antibody ratio (DAR) of $1.4-$ a higher value than previously noted for $5 \mathbf{a}$, which could be explained by an absence of precipitation during the SPAAC with $\mathbf{4 g}$. The cytotoxicity of the ADC $\mathbf{5 g}$ was assayed on the HER2-positive SK-BR-3 and the HER2-negative MDA-MB-231 cancer cell lines, using the FDA-approved trastuzumab emtansine (T-DM1) as a benchmark. Gratifyingly, $\mathbf{5 g}$ was found to be at least as active and selective as T-DM1, with comparable $\mathrm{IC}_{50}$ values on HER2-positive cells and a lack of apparent toxicity on HER2-negative cells (Figure 4, e and Figure S6). 


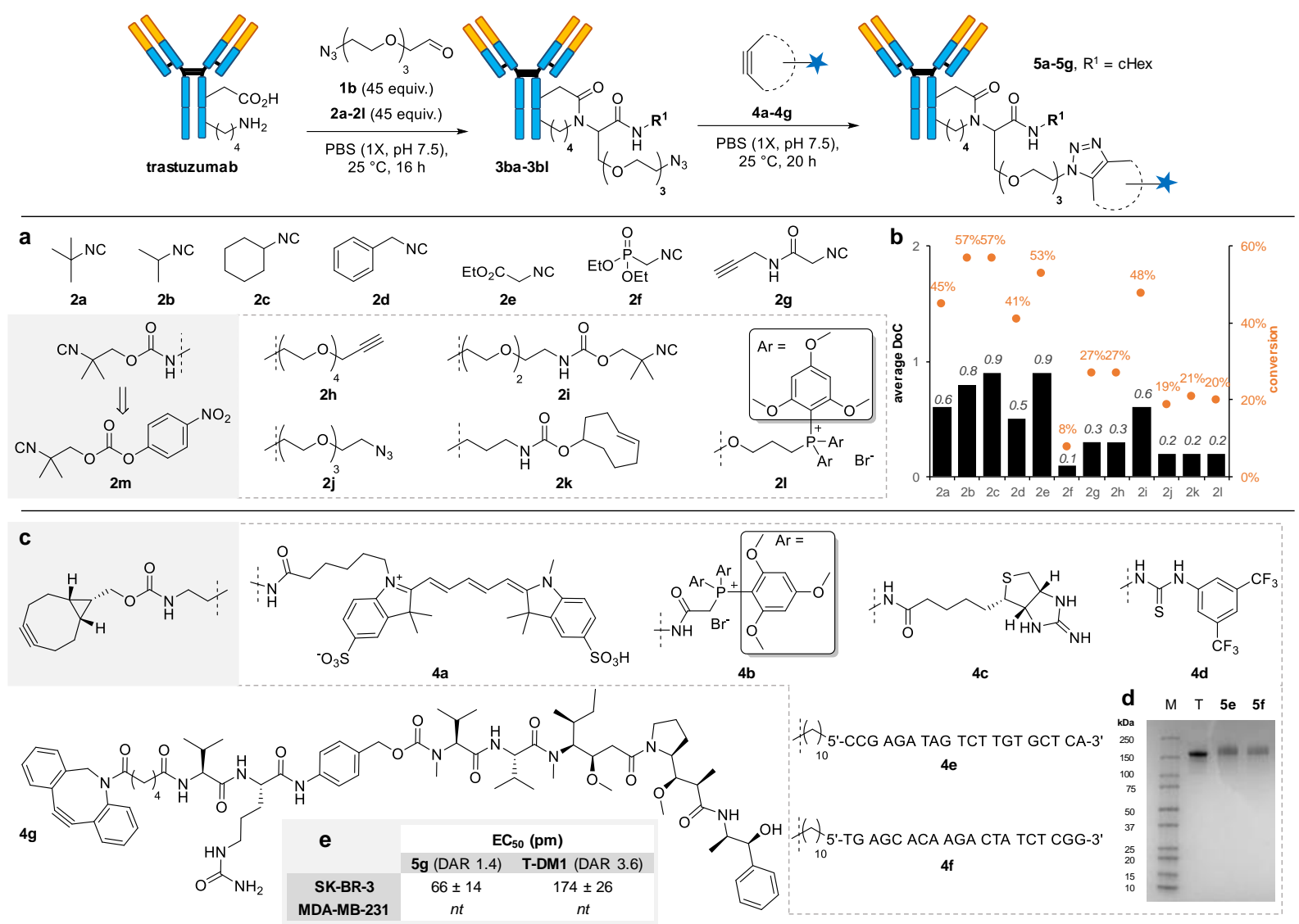

Figure 4: Isocyanide and strained alkynes scope. (a) Isocyanide scope. Reaction conditions: I) $\mathbf{1 b}$ (45 equiv.), 2a-2l (45 equiv.), PBS $1 \times(137 \mathrm{mM} \mathrm{NaCl}, \mathrm{pH} 7.5), 25^{\circ} \mathrm{C}, 16 \mathrm{~h}$; ii) $4 \mathrm{a}$ (10 equiv.), PBS $1 \times(137 \mathrm{mM} \mathrm{NaCl}, \mathrm{pH} 7.5), 25^{\circ} \mathrm{C}, 20 \mathrm{~h}$. (b) Conversion and average DoC values obtained with 2a-2l. (c) Strained alkynes scope. Reaction conditions: i) 1b (45 equiv.), 2a (45 equiv.), PBS $1 \times(137 \mathrm{mM} \mathrm{NaCl}, \mathrm{pH} 7.5), 25^{\circ} \mathrm{C}, 16 \mathrm{~h}$; ii) $\mathbf{4 a}-\mathbf{4 g}$ (10 equiv.), PBS $1 \times(137 \mathrm{mM} \mathrm{NaCl}, \mathrm{pH} 7.5), 25^{\circ} \mathrm{C}, 20 \mathrm{~h}$. (d) Denaturing SDS PAGE analysis of conjugates $\mathbf{5 e}$ and $\mathbf{5 f}$ (M: molecular weight marker; $\mathrm{T}$ : trastuzumab): the multiple bands correspond to the different DoC. (e) Cytotoxicity studies of the ADC $5 \mathbf{g}$ on SK-BR-3 and MDA-MB-231 cancer cell lines ( $n t=$ non-toxic) $-E_{50} \pm$ SD values from two independent experiments.

While the plug-and-play strategy offers a simple and convenient way for the post-derivatization of trastuzumab conjugate $\mathbf{3 b c}$, the use of isocyanides $\mathbf{2 g - 2 k}$, bearing another reactive group, gives an excellent opportunity for dual, and potentially orthogonal, functionalization. We hypothesized that such a double derivatization could be done by either: I) SPAAC followed by copper(I)-catalysed azide alkyne cycloaddition (CuAAC), by combining aldehyde $\mathbf{1 b}$ with isocyanides $\mathbf{2 g}$ or $\mathbf{2 h}$; ii) SPAAC followed by a [4+1] or a [4+2] cycloaddition reaction, with $\mathbf{1 b}$ and $\mathbf{2} \mathbf{i}$ or $\mathbf{2 k}$ respectively; or iii), in a non-orthogonal manner, with a double SPAAC, using $\mathbf{1} \mathbf{b}$ and $\mathbf{2} \mathbf{j}$, for the addition of two equivalents of the same strained alkyne payload. In the latter case, double functionalization of conjugate $\mathbf{3 b j}$ with complete conversion was successfully conducted with alkynes $\mathbf{4 a}$ and $\mathbf{4 c}$, allowing the incorporation of two identical payloads per conjugation site (Figure 5, b). However, orthogonal dual labelling, as detailed in $i$ ) and $i$ ), was only met with failure despite our numerous attempts (see ESI for more details), urging us to seek an alternative route towards this goal. We thus elected aldehyde $\mathbf{1 a}$ and isocyanide $\mathbf{2} \mathbf{j}$ to first conduct the multicomponent conjugation step, giving access to azide-containing conjugate 3aj. Subsequent SPAAC reaction with alkyne $\mathbf{4 c}$ resulted in complete conversion to adduct $5 \mathbf{j}$, successfully incorporating both a fluorescent TAMRA probe and an iminobiotin (Figure S10). While only alkyne 4c was evaluated in this case, the excellent results obtained with such a strategy should easily give access to a plethora of dually functionalized conjugates by simply varying the alkyne component. This strategy thus joins the limited existing group of site-selective dual conjugation methods applicable to native proteins, and most notably, represents the first one to not target cysteine residues to the best of our knowledge. ${ }^{45-47}$ 

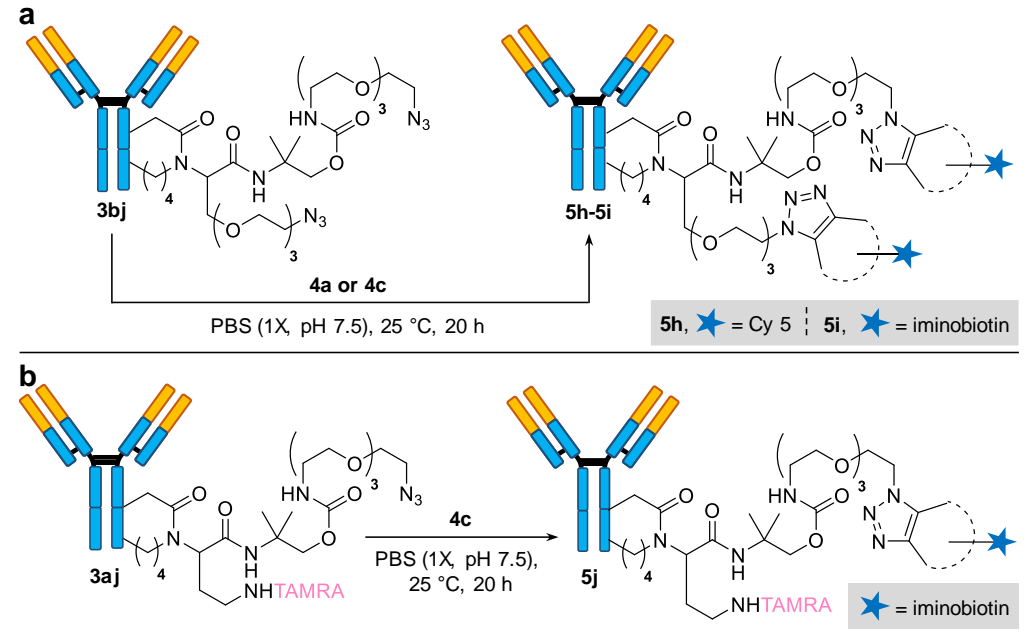

Figure 5: Dual functionalization studies. (a) Homo functionalization by double SPAAC reaction; reaction conditions: 4a or 4c (20 equiv.), PBS $1 \times(137 \mathrm{mM} \mathrm{NaCl}, \mathrm{pH} 7.5), 25^{\circ} \mathrm{C}, 20 \mathrm{~h}$. (b) Hetero functionalization; reaction conditions: $4 \mathrm{c}$ (20 equiv.), PBS 1x $(137 \mathrm{mM} \mathrm{NaCl}, \mathrm{pH} 7.5), 25^{\circ} \mathrm{C}, 20 \mathrm{~h}$.

Having screened various isocyanides and investigated the diversity of payloads that could be incorporated at the play stage of our 'plug-and-play' strategy, we set out to study the aldehyde scope of this transformation, utilising $\mathbf{2} \mathbf{i}$ as a model isocyanide. The previously mentioned TAMRA aldehyde 1a and commercially available aldehydes 1c-1r were thus evaluated and a strong influence of stereoelectronic effects on average DoC and conversion values were observed (Figure 6, a). Degrees and patterns of substitution were found to play an important role as exemplified by linear valeraldehyde 1c giving poor results compared to its branched analogue $\mathbf{1 d}$, or by pivaldehyde $\mathbf{1 g}$, showing a limited reactivity as opposed to isobutyraldehyde $\mathbf{1 e}$ or methyl isopropyl ketone 1f. Interestingly, cyclohexanecarboxaldehyde $\mathbf{1 h}$ yielded better conversion and narrower DoC distribution (D1 to D5) than $\mathbf{1 e}$, a feature already observed when isocyanides $\mathbf{2 b}$ and $\mathbf{2 c}$ were compared. More polar aldehydes 1i1I gave contrasted results: while both glucose and glutaraldehyde failed to conjugate trastuzumab, formaldehyde and glyceraldehyde performed very well, even though the latter gave mass spectra of poor quality, possibly indicating side reactions. Screening aromatic aldehydes, the previously reported 2-pyridinecarboxyaldehyde $\mathbf{1 m}$ was the only one to give positive results, ${ }^{20}$ the five others (1n-1r) leading at best to mediocre conversions and DoC values. While this could be explained by a lack of solubility for compounds $\mathbf{1 q}$ and $\mathbf{1 r}$, the inefficacy of $\mathbf{1 n}$ and $\mathbf{1 0}$ is puzzling, especially considering their known use for the bioconjugation of proteins. ${ }^{48}$ Taken together, these results tend to confirm our hypothesis that the reactive bioconjugation sites could be located in hydrophobic clefts, explaining why small and flexible apolar carbonyls and isocyanides seem to be the best fit for this reaction.

Finally, to close the study of the scope of this new bioconjugation method, our strategy was applied to other native proteins of various sizes: human serum albumin (HSA, $66.5 \mathrm{kDa}$ ), a-chymotrypsin $(25.0 \mathrm{kDa})$, myoglobin $(17.2 \mathrm{kDa})$, lysozyme $(14.3 \mathrm{kDa})$, cytochrome $\mathrm{C}(12.0 \mathrm{kDa})$ and ubiquitin $(8.6 \mathrm{kDa})$ were thus separately incubated with 45 equivalents of 1a and $2 \mathrm{c}$ in PBS $1 \times(137 \mathrm{mM} \mathrm{NaCl}$, $\mathrm{pH} 7.5$ ) for 20 hours at $25^{\circ} \mathrm{C}$. Analyses by native MS showed a conjugation of all but one protein $-\alpha-$ chymotrypsin - with an apparent lack of correlation between the proteins' sizes and both the average DoC and conversion rates (Figure $6, b$ ). Interestingly, conjugation of lysozyme and HSA only gave monofunctionalized adducts (D1 species), a remarkable feature in the case of HSA considering its size and the good conversion observed. 

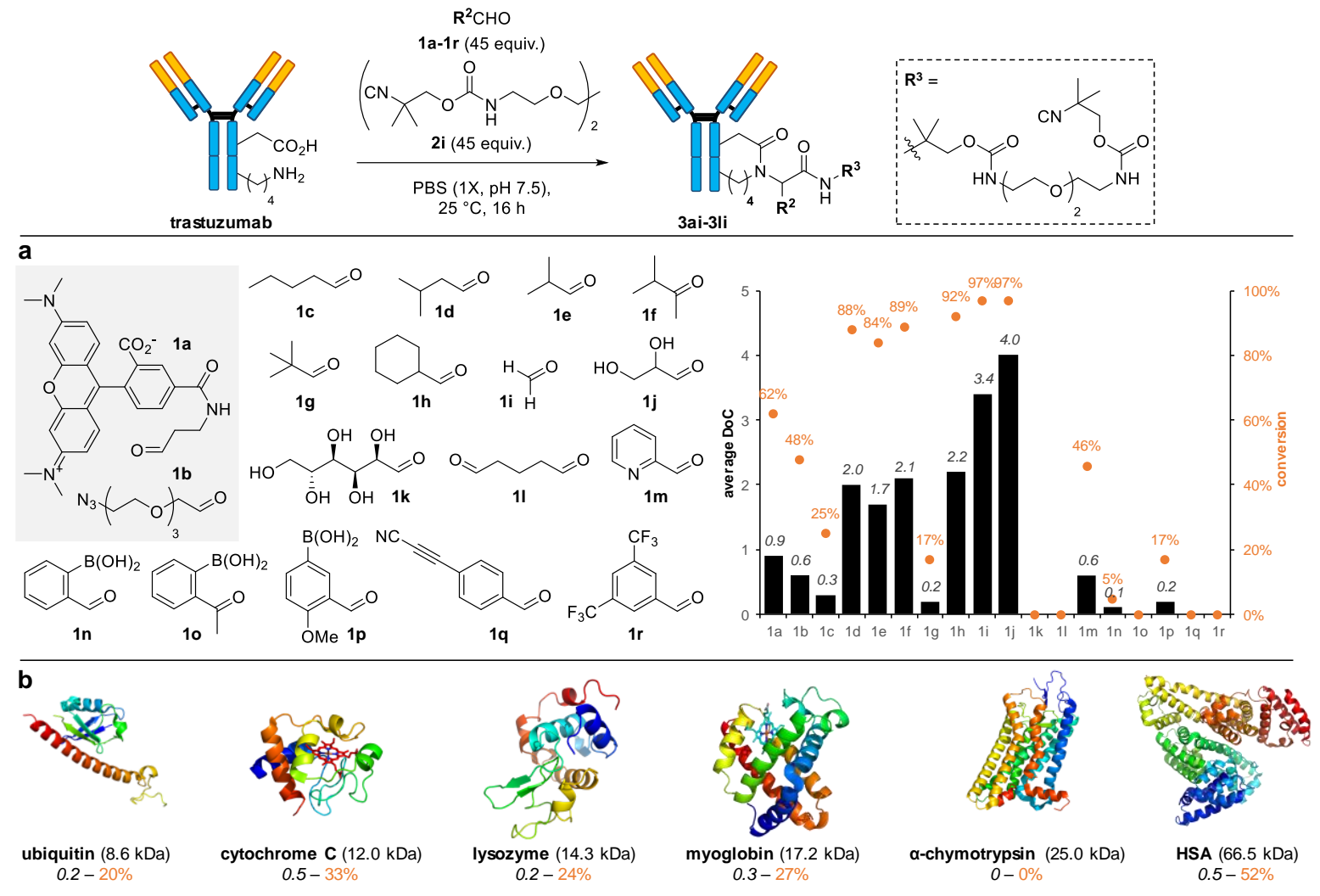

Figure 6: Aldehyde and protein scopes of the multicomponent bioconjugation reaction. (a) Aldehyde scope. Reaction conditions: 1a-1r (45 equiv.), 2i (45 equiv.), PBS $1 \times(137 \mathrm{mM} \mathrm{NaCl}, \mathrm{pH} 7.5), 25^{\circ} \mathrm{C}, 16 \mathrm{~h}$. (b) Protein scope. Reaction conditions: 1 a (45 equiv.), 2c (45 equiv.), PBS $1 \times(137 \mathrm{mM} \mathrm{NaCl}, \mathrm{pH} 7.5), 25^{\circ} \mathrm{C}, 16 \mathrm{~h}$.

Having developed an efficient, operationally simple and quick multicomponent bioconjugation strategy that tolerates various reactive groups and substrates, we turned to LC-MS/MS studies to validate the mechanism of the bioconjugation reaction and localize the exact conjugation sites in order to find out whether our strategy could be coined site-specific. Given the interest in site-specific native antibody conjugation, we solely focused these studies on trastuzumab conjugates. Peptide mapping was thus conducted on three separate batches that were prepared and purified in different manners. A first batch of $5 \mathbf{a}$ with an average DoC of 0.6 was generated from conjugate $3 \mathbf{b c}$ after SPAAC with the BCN-cyanine$5 \mathrm{4a}$ and analysed without further purification (protein sequence coverage: $100 \%$ ). Due to the presence of unconjugated trastuzumab yielding peptides that outcompeted the conjugated fragments for mass detection, two enriched batches were produced by two similar but distinct routes (protein sequence coverage: $31-48 \%$ ). A first strategy utilized conjugate $\mathbf{5 c}-$ synthesized from $\mathbf{3 b c}$ and the BCN-biotin derivative 4c. Trypsin digestion followed by affinity purification of the digestate on streptavidin column gave a first enriched sample. A second strategy inverted the order of events: conjugate $3 \mathbf{b c}$ was digested before the functionalization with strained alkyne 4c. The resulting mixture of peptides was then enriched in the same manner as for the first strategy (see ESI for more details). Taken altogether, these analyses highlighted six conjugation sites, only two of which being detected in all three batches: the $\mathrm{N}$ terminal glutamate (E1) of the heavy chain, and the $N$-terminal aspartate (D1) of the light chain. Remarkably, both of these residues partook in two different types of multicomponent reaction: an intramolecular U-4C-3R, yielding $\beta$ - and $\gamma$-lactams (from D1 and E1 respectively), and a Passerini reaction, involving only the side chains carboxylate functions (detected only in the two enriched samples for D1, but in all three batches for E1). The four other conjugation sites were all detected in only a single batch and could thus not be cross-validated. Three of them were found to correspond to glutamate residues modified by a Passerini reaction: the light-chain E195, and the heavy-chain E236 and E348. The expected inter-residue U-4C-3R was finally found to be responsible for the fourth conjugation site detected, located on the light chain and involving the side chains of K126 and either D122 or E123 (undistinguishable from each other). Interestingly, the heavy-chain $C$-terminal lysine (K478) did not react in either a U-4C-3R or a Passerini reaction, and was found to be unaffected.

While the number of modification sites on trastuzumab is certainly too high to call this strategy sitespecific, the $\mathrm{N}$-terminal modification of both chains coupled to the excellent aspartate/glutamate 
selectivity and the first example of a dual residue modification represent extremely interesting features that could open new avenues towards the development of native antibodies site-specific conjugation strategies.

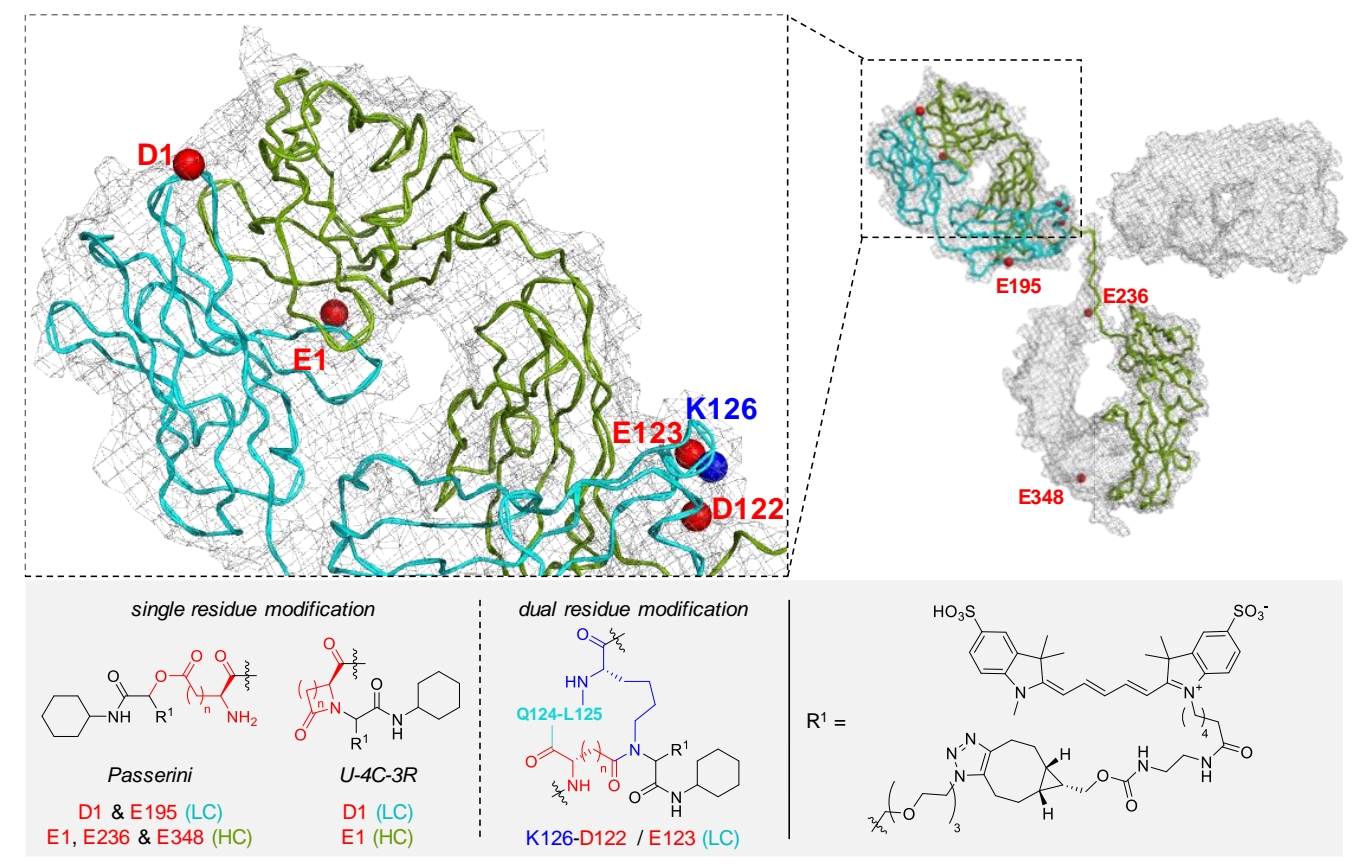

Figure 7: Trastuzumab conjugation sites determined by peptide mapping

In conclusion, we reported the use of a new multicomponent strategy for the conjugation of various native proteins. By combining commercially available - or easily accessible - aldehydes and isocyanides, this modular approach gives a facile and rapid access to functionalized proteins incorporating various payloads. Most notably, this strategy was used to synthesize a trastuzumab-based ADC that retained its selectivity towards HER2-positive cancer cell lines and was found to be as active as the benchmark T-DM1. Two reactions were proved to compete with each other in this conjugation process, the expected Ugi four-centre three-component reaction (U-4C-3R) and the Passerini reaction, both of which occurred at the $\mathrm{N}$-terminal aspartate and glutamate residues. While not being fully effective at the present, such an approach could be an excellent stepping stone towards the development of a yet unreported $\mathrm{N}$-terminal-Asp/Glu selective strategy. Moreover, this strategy represents the first example of an aspartate/glutamate selective conjugation method that is not using activating agents for their intermediate conversion to activated esters - strategies that often yield undesired protein crosslinking. Overall, these results offer a new approach towards a site-specific bioconjugation strategy that could be applied to native proteins and highlight the potential of multicomponent reactions for this purpose.

\section{Supporting Information}

The Supporting Information includes: Experimental procedures and characterization, additional information, Figures S1-S13, Tables S1-S4, and NMR spectra of newly synthesized compounds.

\section{Author Information}

Corresponding Author:

*chaubet@unistra.fr

\section{Author Contributions}

The work was conceived by G.C. All reactions were carried out by C.S. Cytotoxic studies were done by I.D. Native mass spectrometry analyses and peptide mapping were performed by S.H., S.E, A. E. and T. B. The manuscript was written through contributions of all authors. All authors have given approval to the final version of the manuscript.

\section{Funding Sources}


This work was supported by the CNRS, the University of Strasbourg and the French Proteomic Infrastructure (ProFI; ANR-10-INBS-08-03). The authors would like to thank GIS IBiSA and Région Alsace for financial support in purchasing Synapt G2 HDMS and Orbitrap Exactive Plus EMR instruments, respectively. C.S. thanks the "Région Grand-Est" and "LabEx MEDALIS" for a PhD studentship. A.E. acknowledges the "Association Nationale de la Recherche et de la Technologie" (ANRT) and Syndivia for funding his PhD fellowship.

\section{Acknowledgment}

We thank Marc Nothisen for cell cultures, Dr Oleksandr Koniev and Dr Sergii Kolodych for insightful discussions.

\section{References}

(1) Walsh, C. T.; Garneau-Tsodikova, S.; Gatto, G. J. Protein Posttranslational Modifications: The Chemistry of Proteome Diversifications. Angew. Chem. Int. Ed. 2005, 44 (45), 7342-7372. https://doi.org/10.1002/anie.200501023.

(2) Walsh, C. T. Posttranslational Modification of Proteins: Expanding Nature's Inventory; Roberts: Englewood, Colo, 2006.

(3) Harlan, J. W.; Feairheller, S. H. Chemistry of the Crosslinking of Collagen during Tanning. In Protein Crosslinking; Friedman, M., Ed.; Springer US: Boston, MA, 1977; Vol. 86A, pp 425-440. https://doi.org/10.1007/978-1-4684-3282-4_27.

(4) Means, G. E.; Feeney, R. E. Chemical Modifications of Proteins: History and Applications. Bioconjug. Chem. 1990, 1 (1), 2-12. https://doi.org/10.1021/bc00001a001.

(5) Rees, A. R. The Antibody Molecule: From Antitoxins to Therapeutic Antibodies; Oxford University Press, 2014. https://doi.org/10.1093/med/9780199646579.001.0001.

(6) Shreder, K. Synthetic Haptens as Probes of Antibody Response and Immunorecognition. Methods 2000, 20 (3), 372-379. https://doi.org/10.1006/meth.1999.0929.

(7) Spicer, C. D.; Davis, B. G. Selective Chemical Protein Modification. Nat. Commun. 2014, 5, 4740. https://doi.org/10.1038/ncomms5740.

(8) deGruyter, J. N.; Malins, L. R.; Baran, P. S. Residue-Specific Peptide Modification: A Chemist's Guide. Biochemistry (Mosc.) 2017, 56 (30), 3863-3873. https://doi.org/10.1021/acs.biochem.7b00536.

(9) Rabuka, D. Chemoenzymatic Methods for Site-Specific Protein Modification. Curr. Opin. Chem. Biol. 2010, 14 (6), 790-796. https://doi.org/10.1016/j.cbpa.2010.09.020.

(10) Krall, N.; da Cruz, F. P.; Boutureira, O.; Bernardes, G. J. L. Site-Selective Protein-Modification Chemistry for Basic Biology and Drug Development. Nat. Chem. 2016, 8 (2), 103-113. https://doi.org/10.1038/nchem.2393.

(11) Stephanopoulos, N.; Francis, M. B. Choosing an Effective Protein Bioconjugation Strategy. Nat. Chem. Biol. 2011, 7 (12), 876-884. https://doi.org/10.1038/nchembio.720.

(12) Koniev, O.; Wagner, A. Developments and Recent Advancements in the Field of Endogenous Amino Acid Selective Bond Forming Reactions for Bioconjugation. Chem. Soc. Rev. 2015, 44 (15), 5495-5551. https://doi.org/10.1039/C5CS00048C.

(13) Sakamoto, S.; Hamachi, I. Recent Progress in Chemical Modification of Proteins. Anal. Sci. 2019,35 (1), 5-27. https://doi.org/10.2116/analsci.18R003.

(14) Kuan, S. L.; Wang, T.; Weil, T. Site-Selective Disulfide Modification of Proteins: Expanding Diversity beyond the Proteome. Chem. - Eur. J. 2016, 22 (48), 17112-17129. https://doi.org/10.1002/chem.201602298.

(15) Walsh, S. J.; Omarjee, S.; Galloway, W. R. J. D.; Kwan, T. T.-L.; Sore, H. F.; Parker, J. S.; Hyvönen, M.; Carroll, J. S.; Spring, D. R. A General Approach for the Site-Selective Modification of Native Proteins, Enabling the Generation of Stable and Functional Antibody-Drug Conjugates. Chem. Sci. 2019, 10 (3), 694-700. https://doi.org/10.1039/C8SC04645J.

(16) Maruani, A.; Smith, M. E. B.; Miranda, E.; Chester, K. A.; Chudasama, V.; Caddick, S. A Plug-and-Play Approach to Antibody-Based Therapeutics via a Chemoselective Dual Click Strategy. Nat. Commun. 2015, 6 (1). https://doi.org/10.1038/ncomms7645.

(17) Smith, M. E. B.; Schumacher, F. F.; Ryan, C. P.; Tedaldi, L. M.; Papaioannou, D.; Waksman, G.; Caddick, S.; Baker, J. R. Protein Modification, Bioconjugation, and Disulfide Bridging Using Bromomaleimides. J. Am. Chem. Soc. 2010, 132 (6), 1960-1965. https://doi.org/10.1021/ja908610s.

(18) Lee, M. T. W.; Maruani, A.; Baker, J. R.; Caddick, S.; Chudasama, V. Next-Generation Disulfide Stapling: Reduction and Functional Re-Bridging All in One. Chem. Sci. 2015, 7 (1), 799-802. https://doi.org/10.1039/C5SC02666K

(19) Gilmore, J. M.; Scheck, R. A.; Esser-Kahn, A. P.; Joshi, N. S.; Francis, M. B. N-Terminal Protein Modification through a Biomimetic Transamination Reaction. Angew. Chem. Int. Ed. 2006, 45 (32), 5307-5311. https://doi.org/10.1002/anie.200600368.

(20) MacDonald, J. I.; Munch, H. K.; Moore, T.; Francis, M. B. One-Step Site-Specific Modification of Native Proteins with 2-Pyridinecarboxyaldehydes. Nat. Chem. Biol. 2015, 11 (5), 326-331. https://doi.org/10.1038/nchembio.1792.

(21) Chen, D.; Disotuar, M. M.; Xiong, X.; Wang, Y.; Chou, D. H.-C. Selective N-Terminal Functionalization of Native Peptides and Proteins. Chem. Sci. 2017, 8 (4), 2717-2722. https://doi.org/10.1039/C6SC04744K. 
(22) Li, D.; Han, B.; Wei, R.; Yao, G.; Chen, Z.; Liu, J.; Poon, T. C. W.; Su, W.; Zhu, Z.; Dimitrov, D. S.; Zhao, Q. N-Terminal $\alpha$-Amino Group Modification of Antibodies Using a Site-Selective Click Chemistry Method. $m A b s$ 2018, 10 (5), 712-719. https://doi.org/10.1080/19420862.2018.1463122.

(23) Chan, A. O.-Y.; Ho, C.-M.; Chong, H.-C.; Leung, Y.-C.; Huang, J.-S.; Wong, M.-K.; Che, C.-M. Modification of N-Terminal a-Amino Groups of Peptides and Proteins Using Ketenes. J. Am. Chem. Soc. 2012, 134 (5), 2589-2598. https://doi.org/10.1021/ja208009r.

(24) Kodal, A. L. B.; Rosen, C. B.; Mortensen, M. R.; Tørring, T.; Gothelf, K. V. DNA-Templated Introduction of an Aldehyde Handle in Proteins. ChemBioChem 2016, 17 (14), 1338-1342. https://doi.org/10.1002/cbic.201600254.

(25) Lac, D.; Feng, C.; Bhardwaj, G.; Le, H.; Tran, J.; Xing, L.; Fung, G.; Liu, R.; Cheng, H.; Lam, K. S. Covalent Chemical Ligation Strategy for Mono- and Polyclonal Immunoglobulins at Their Nucleotide Binding Sites. Bioconjug. Chem. 2016, 27 (1), 159-169. https://doi.org/10.1021/acs.bioconjchem.5b00574.

(26) Hui, J. Z.; Tamsen, S.; Song, Y.; Tsourkas, A. LASIC: Light Activated Site-Specific Conjugation of Native IgGs. Bioconjug. Chem. 2015, 26 (8), 1456-1460. https://doi.org/10.1021/acs.bioconjchem.5b00275.

(27) Zhang, Y.; Liang, Y.; Huang, F.; Zhang, Y.; Li, X.; Xia, J. Site-Selective Lysine Reactions Guided by ProteinPeptide Interaction. Biochemistry (Mosc.) 2019, 58 (7), 1010-1018. https://doi.org/10.1021/acs.biochem.8b01223.

(28) Yu, C.; Tang, J.; Loredo, A.; Chen, Y.; Jung, S. Y.; Jain, A.; Gordon, A.; Xiao, H. Proximity-Induced SiteSpecific Antibody Conjugation. Bioconjug. Chem. 2018, 29 (11), 3522-3526. https://doi.org/10.1021/acs.bioconjchem.8b00680.

(29) Matos, M. J.; Oliveira, B. L.; Martínez-Sáez, N.; Guerreiro, A.; Cal, P. M. S. D.; Bertoldo, J.; Maneiro, M.; Perkins, E.; Howard, J.; Deery, M. J.; Chalker, J. M.; Corzana, F.; Jiménez-Osés, G.; Bernardes, G. J. L. Chemo- and Regioselective Lysine Modification on Native Proteins. J. Am. Chem. Soc. 2018, 140 (11), 4004-4017. https://doi.org/10.1021/jacs.7b12874.

(30) Adusumalli, S. R.; Rawale, D. G.; Singh, U.; Tripathi, P.; Paul, R.; Kalra, N.; Mishra, R. K.; Shukla, S.; Rai, V. Single-Site Labeling of Native Proteins Enabled by a Chemoselective and Site-Selective Chemical Technology. J. Am. Chem. Soc. 2018, 140 (44), 15114-15123. https://doi.org/10.1021/jacs.8b10490.

(31) Chaubet, G.; Thoreau, F.; Wagner, A. Recent, Non-Classical, Approaches to Antibody Lysine Modification. Drug Discov. Today Technol. 2018, 30, 21-26. https://doi.org/10.1016/j.ddtec.2018.09.002.

(32) Medeiros, G. A.; Silva, W. A. da; Bataglion, G. A.; Ferreira, D. A. C.; Oliveira, H. C. B. de; Eberlin, M. N.; Neto, B. A. D. Probing the Mechanism of the Ugi Four-Component Reaction with Charge-Tagged Reagents by ESI-MS(/MS). Chem. Commun. 2013, 50 (3), 338-340. https://doi.org/10.1039/C3CC47156J.

(33) lacobucci, C.; Reale, S.; Gal, J.-F.; Angelis, F. D. Insight into the Mechanisms of the Multicomponent Ugi and Ugi-Smiles Reactions by ESI-MS(/MS). Eur. J. Org. Chem. 2014, 2014 (32), 7087-7090. https://doi.org/10.1002/ejoc.201403179.

(34) Marek, M.; Jarý, J.; Valentová, O.; Vodrážka, Z. Immobilization of Glycoenzymes by Means of Their Glycosidic Components. Biotechnol. Lett. 1983, 5 (10), 653-658. https://doi.org/10.1007/BF01386357.

(35) Ziegler, T.; Gerling, S.; Lang, M. Preparation of Bioconjugates through an Ugi Reaction. Angew. Chem. Int. Ed. 2000, 39 (12), 2109-2112. https://doi.org/10.1002/1521-3773(20000616)39:12<2109::AIDANIE2109>3.0.CO;2-9.

(36) Méndez, Y.; Chang, J.; Humpierre, A. R.; Zanuy, A.; Garrido, R.; Vasco, A. V.; Pedroso, J.; Santana, D.; Rodríguez, L. M.; García-Rivera, D.; Valdés, Y.; Vérez-Bencomo, V.; Rivera, D. G. Multicomponent Polysaccharide-Protein Bioconjugation in the Development of Antibacterial Glycoconjugate Vaccine Candidates. Chem. Sci. 2018, 9 (9), 2581-2588. https://doi.org/10.1039/C7SC05467J.

(37) García, A.; Hernández, K.; Chico, B.; García, D.; Villalonga, M. L.; Villalonga, R. Preparation of Thermostable Trypsin-Polysaccharide Neoglycoenzymes through Ugi Multicomponent Reaction. J. Mol. Catal. B Enzym. 2009, 59 (1-3), 126-130. https://doi.org/10.1016/j.molcatb.2009.02.001.

(38) Camacho, C.; Matías, J. C.; García, D.; Simpson, B. K.; Villalonga, R. Amperometric Enzyme Biosensor for Hydrogen Peroxide via Ugi Multicomponent Reaction. Electrochem. Commun. 2007, 9 (7), 1655-1660. https://doi.org/10.1016/j.elecom.2007.03.013.

(39) Nahta, R.; Esteva, F. J. Trastuzumab: Triumphs and Tribulations. Oncogene 2007, 26 (25), 3637-3643. https://doi.org/10.1038/sj.onc.1210379.

(40) Marcaccini, S.; Torroba, T. The Use of the Ugi Four-Component Condensation. Nat. Protoc. 2007, 2 (3), 632-639. https://doi.org/10.1038/nprot.2007.71.

(41) Dömling, A.; Ugi, I. Multicomponent Reactions with Isocyanides. Angew. Chem. Int. Ed. 2000, 39 (18), 3168-3210. https://doi.org/10.1002/1521-3773(20000915)39:18<3168::AID-ANIE3168>3.0.CO;2-U.

(42) Dovgan, I.; Ursuegui, S.; Erb, S.; Michel, C.; Kolodych, S.; Cianférani, S.; Wagner, A. Acyl Fluorides: Fast, Efficient, and Versatile Lysine-Based Protein Conjugation via Plug-and-Play Strategy. Bioconjug. Chem. 2017, 28 (5), 1452-1457. https://doi.org/10.1021/acs.bioconjchem.7b00141.

(43) Dovgan, I.; Erb, S.; Hessmann, S.; Ursuegui, S.; Michel, C.; Muller, C.; Chaubet, G.; Cianférani, S.; Wagner, A. Arginine-Selective Bioconjugation with 4-Azidophenyl Glyoxal: Application to the Single and Dual Functionalisation of Native Antibodies. Org. Biomol. Chem. 2018, 16 (8), 1305-1311. https://doi.org/10.1039/C7OB02844J.

(44) Stöckmann, H.; Neves, A. A.; Stairs, S.; Brindle, K. M.; Leeper, F. J. Exploring Isonitrile-Based Click Chemistry for Ligation with Biomolecules. Org. Biomol. Chem. 2011, 9 (21), 7303-7305. https://doi.org/10.1039/C1OB06424J. 
(45) Maruani, A.; Richards, D. A.; Chudasama, V. Dual Modification of Biomolecules. Org. Biomol. Chem. 2016, 14 (26), 6165-6178. https://doi.org/10.1039/C6OB01010E.

(46) Maruani, A.; Smith, M. E. B.; Miranda, E.; Chester, K. A.; Chudasama, V.; Caddick, S. A Plug-and-Play Approach to Antibody-Based Therapeutics via a Chemoselective Dual Click Strategy. Nat. Commun. 2015, 6 (1), 1-9. https://doi.org/10.1038/ncomms7645.

(47) Agrawalla, B. K.; Wang, T.; Riegger, A.; Domogalla, M. P.; Steinbrink, K.; Dörfler, T.; Chen, X.; Boldt, F.; Lamla, M.; Michaelis, J.; Kuan, S. L.; Weil, T. Chemoselective Dual Labeling of Native and Recombinant Proteins. Bioconjug. Chem. 2018, 29 (1), 29-34. https://doi.org/10.1021/acs.bioconjchem.7b00675.

(48) Cambray, S.; Gao, J. Versatile Bioconjugation Chemistries of Ortho-Boronyl Aryl Ketones and Aldehydes. Acc. Chem. Res. 2018, 51 (9), 2198-2206. https://doi.org/10.1021/acs.accounts.8b00154. 